\title{
Four cases of traumatic hypotony maculopathy treated by various methods
}

This article was published in the following Dove Press journal:

Clinical Ophthalmology

26 August 2011

Number of times this article has been viewed

\section{Tetsuya Mutoh \\ Yukihiro Matsumoto \\ Makoto Chikuda \\ Department of Ophthalmology, Dokkyo Medical University Koshigaya Hospital, Koshigaya, Saitama, Japan}

Correspondence: Tetsuya Mutoh Department of Ophthalmology, Dokkyo Medical University Koshigaya Hospital, Koshigaya, Saitama 343-8555, Japan

Tel +8 I 48965 I I I I

$\mathrm{Fax}+8 \mid 48965$ । I 27

Email onihei@bu.edu
Abstract: Several reports have been published on methods for treating hypotony maculopathy. Currently, the preferred choice of treatment depends on the severity of the illness. We experienced four cases of traumatic hypotony maculopathy and treated them by various methods. Cases 1-3 were treated by various surgical treatments. Case 1 was treated by combined cataract surgery and pars plana vitrectomy. The vitreous cavity was replaced with $20 \%$ sulfur hexafluoride (SF6). Case 2 did not improve with laser trabeculoplasty, so further encircling was performed. Case 3 did not improve with photocoagulation of the ciliary body and injection of 20\% SF6 into the vitreous cavity. Consequently, this case required suturing of the ciliary body to the sclera, cryopexy for the ciliary body, and injection of $100 \%$ SF6. Case 4 was treated only with eye drops. Intraocular pressure (IOP) increased in all cases as a result of treatment. Treatment improved hypotony maculopathy in all cases. Pre-treatment visual acuities ranged from 0.03 to 0.4 , with IOP ranging from 2 to $10 \mathrm{mmHg}$. Post-treatment visual acuity ranged from 0.09 to 1.2 , with IOP ranging from 14 to $16 \mathrm{mmHg}$. Only case 2 resulted in poor visual prognosis because of choroidal rupture near the foveola. The difficulty in choosing treatment methods lies in the need for multiple surgical treatments for some cases. Effective and noninvasive treatment methods are expected to be established in the future.

Keywords: traumatic hypotony maculopathy, surgical treatment, eye drops, treatment method

\section{Introduction}

Hypotony maculopathy, first described by Dellaporta in 1954, occurs usually after antiglaucomatous surgery or after perforating eye injuries. ${ }^{1}$ The condition is characterized by hypotony associated with fundus abnormalities, including papilloedema, vascular tortuosity, and chorioretinal folds. ${ }^{1}$

Once the cause is known, patients should be treated as soon as possible because delayed normalization of the intraocular pressure (IOP) may result in permanent macular chorioretinal changes and poor vision. ${ }^{2}$ On the other hand, one case was reported in which visual acuity was maintained at 1.2 in spite of traumatic hypotony maculopathy. ${ }^{3}$

Laser photocoagulation, ${ }^{4,5}$ gas tamponade, ${ }^{5,6}$ diathermic coagulation, ${ }^{7}$ cataract extraction and scleral fixation of intraocular lenses, ${ }^{8,9}$ suturing the ciliary body to the sclera, ${ }^{7}$ cryopexy, ${ }^{6,7}$ scleral buckling of the dissociated part, ${ }^{5,710,11}$ encircling, ${ }^{7,12}$ and pars plana vitrectomy ${ }^{6,7}$ have been reported as the treatment methods of traumatic hypotony maculopathy. Many cases were performed combining several treatment methods, ${ }^{5-7,10-12}$ while some cases did not require surgery. ${ }^{7}$ According to Brown et al the treatment choice 
depends on the existence and type of cyclodialysis, the visual impairment, and duration of hypotony maculopathy. ${ }^{13}$

We experienced four cases of traumatic hypotony maculopathy treated by various methods. IOP increased in all cases as a result of treatment.

\section{Case reports Case I}

On October 15, 2007, a 52-year-old man was referred to Dokkyo Medical University Koshigaya Hospital for traumatic hypotony maculopathy in his right eye after he had been punched in the face by his son 1 year previously. Best corrected visual acuity was 0.4 , IOP was $4 \mathrm{mmHg}$, and corneal endothelial cell density was 2646 cells $/ \mathrm{mm}^{2}$ in the right eye. Ophthalmoscopy revealed chorioretinal folds in the macula area. Gonioscopy showed a cyclodialysis cleft from 5 to 7 o'clock. Fluoroscein angiography confirmed macular folds and blood vessel crawling. Phacoemulsification, triamcinolone-assisted pars plana vitrectomy to achieve a posterior vitreous detachment, epiretinal membrane and inner limiting membrane peeling dying indocyanine green, and a $20 \%$ sulfur hexafluoride (SF6) gas tamponade were performed on July 3, 2008. The IOP was normalized soon after surgery, the best corrected visual acuity improved to 0.8 and the corneal endothelial cell density was 2639 cells $/ \mathrm{mm}^{2}$. A second implant of an intraocular lens was performed on July 23, 2008. At the last follow-up examination 11 months after the initial visit, visual acuity was 0.9 , IOP was $16 \mathrm{mmHg}$, and the corneal endothelial cell density was $713 \mathrm{cells} / \mathrm{mm}^{2}$.

\section{Case 2}

On November 1, 2006, a 30-year-old man was referred to Dokkyo Medical University Koshigaya Hospital for treatment of hyphema in his left eye after a golf ball had struck him 3 days prior. Anterior photograph confirmed the presence of hyphema and mydriatic pupil. Best corrected visual acuity was 0.03 , and the IOP was $2 \mathrm{mmHg}$. When the hyphema disappeared 6 days after the initial visit, a vitreous hemorrhage was found. When the vitreous hemorrhage disappeared 3 weeks later, ophthalmoscopy revealed chorioretinal folds in the macula area. No cyclodialysis was found by gonioscopy. Because medical treatment with topical atropine sulfate and steroid eye drops had no effect on hypotony, laser trabeculoplasty from 2 to 9 o'clock was performed, but the IOP in his left eye remained low. Fluoroscein angiography 3 months after eye trauma revealed choroidal rupture and retinal concussion necrosis. Encircling was performed on February 20, 2007. IOP was normalized soon after surgery, and best corrected visual acuity was 0.08 . At the last follow-up examination 2 years after eye trauma, visual acuity was 0.09 and IOP was $14 \mathrm{mmHg}$.

\section{Case 3}

On July 1, 2001, a 37-year-old man came to the emergency room of Dokkyo Medical University Koshigaya Hospital for treatment of hyphema after a baseball hit him in the left eye. Best corrected visual acuity was 0.06 and the IOP was $10 \mathrm{mmHg}$. When the hyphema disappeared 7 days after the trauma, ophthalmoscopy revealed subretinal and vitreous hemorrhages. Gonioscopy showed a cyclodialysis cleft from 5 to 7 o'clock and lens donasis. When the vitreous hemorrhage disappeared 2 weeks later, ophthalmoscopy revealed chorioretinal folds in the macula area. Two surgical procedures (laser photocoagulation to the ciliary body and 20\% SF6 gas injection into the vitreous cavity) were performed, but the IOP in the left eye remained low. Suturing the ciliary body to the sclera, cryopexy for the ciliary body, and injection of 100\% SF6 were performed on August 21, 2001. IOP normalized soon after surgery. At the last follow-up examination 8 years after eye trauma, visual acuity was 0.8 and the IOP was $15 \mathrm{mmHg}$.

\section{Case 4}

On January 15, 2007, a 41-year-old woman was referred to Dokkyo Medical University Koshigaya Hospital for eye trauma in her left eye, caused by a blow to the face with a golf club 4 days prior. Best corrected visual acuity was 0.1 , and the IOP was $8 \mathrm{mmHg}$ in this eye. Slit lamp examination showed a hyphema and gonioscopy showed no cyclodialysis cleft. However, IOP remained less than $10 \mathrm{mmHg}$ after the initial visit and ophthalmoscopy revealed chorioretinal folds in the macula area 4 weeks after eye trauma (Figure 1). Although the IOP remained low, preservative treatment without surgery was continued because 2 months after eye trauma her best corrected visual acuity had improved to 1.2. IOP rose gradually and chorioretinal folds almost disappeared 2 years after eye trauma (Figure 2). At the last follow-up examination 3.5 years after eye trauma, visual acuity was 1.2 and IOP was $14 \mathrm{mmHg}$.

\section{Discussion}

The first surgery raised the IOP in case 1 , while cases 2 and 3 required multiple surgeries to increase IOP. Although the patient in case 4 had low IOP, surgery was not performed because 2 months after eye trauma visual acuity improved to 1.2. Inoue et al reported six cases of hypotony 


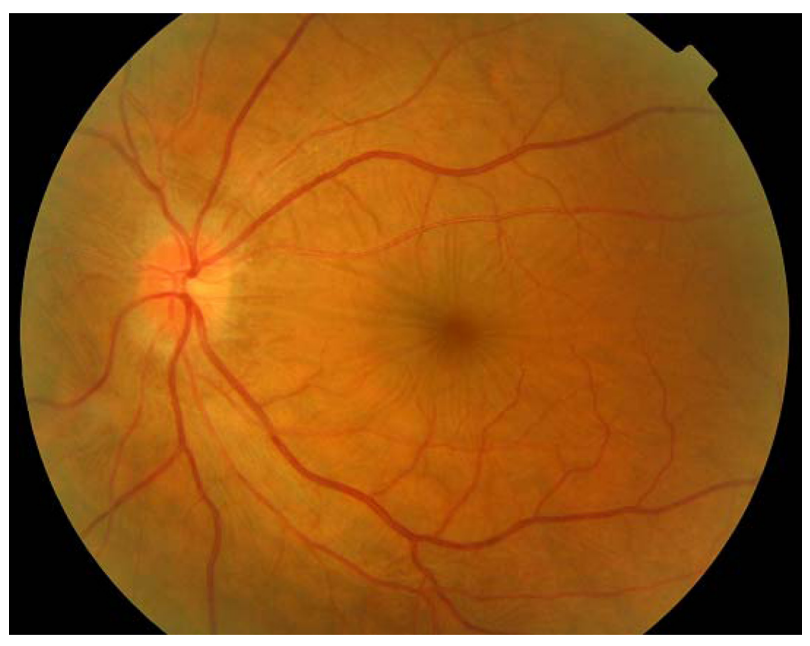

Figure I Fundus photograph of case 4. Left eye 4 weeks after eye trauma. Macular folds.

maculopathy treated using only eye drops and oral drugs. ${ }^{7}$ In five out of these six cases, the IOP rose to more than $10 \mathrm{mmHg}$ and patients improved more than four steps of visual acuity within a month of initial treatment. Although it took 2 years to normalize the IOP, our patient in case 4 improved by four steps of visual acuity 2 months after eye trauma. Visual acuity improved dramatically in spite of the presence of hypotony maculopathy. IOP changed from 6 to $10 \mathrm{mmHg}$, and this relatively high IOP may have affected the positive outcome. On the other hand, Brandonisio and Newman reported a case of good visual prognosis with excessively low IOP at $2 \mathrm{mmHg}$ in traumatic hypotony maculopathy. ${ }^{3}$ Such cases seem to be very rare.

Cyclodialysis was found in cases 1 and 3. Cyclodialysis could not be found in case 2 and it did not exist in case 4 . However, it is difficult to accurately find cyclodialysis in hypotony maculopathy because the anterior chamber is very shallow in

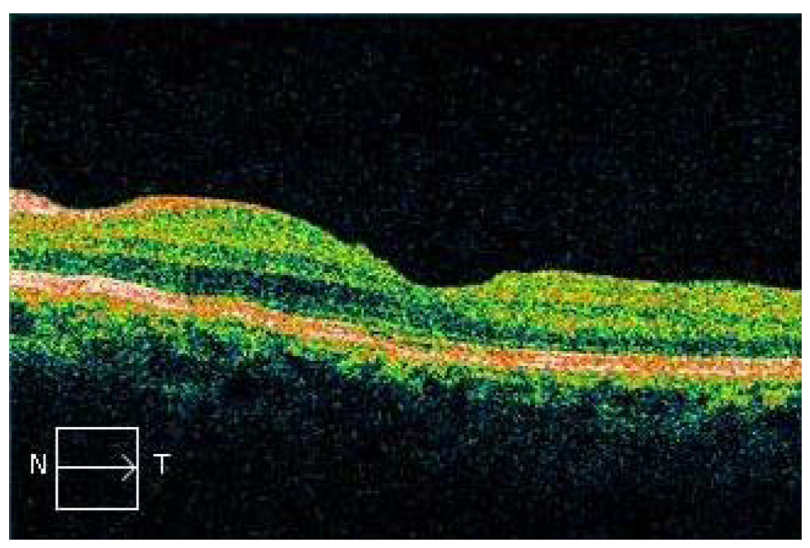

Figure 2 Optical coherence tomograph of case 4. Left eye 2 years after eye trauma. Macular folds have almost disappeared. general. Sometimes cyclodialysis exists but cannot be found through inspection with the unaided eye. ${ }^{14}$ Consequently, it is important to consider gonioscopy as a reference.

Only case 2 , in which a choroidal rupture developed near the foveola, did not reach a final best corrected visual acuity of 0.1. Chorioretinal degeneration of the foveola was not caused by low IOP. Choroidal rupture and retinal concussion necrosis was caused by a golf ball. Weitgasser et al reported that the visual prognosis is very poor in golf-related injuries and three out of seven cases needed enucleation..$^{15}$ Townley et al reported that seven out of ten cases of golf-related eye injuries required enucleation or evisceration..$^{16}$ Although case 4 was an eye trauma caused by a golf club, visual acuity fortunately improved without surgery. Although golf is a popular sport, golfers should be more aware of this danger.

Takaya et al reported that visual prognosis was poor in only one out of four traumatic hypotony maculopathy cases; and in this case, choroidal rupture developed at the foveola. ${ }^{6}$ Data from multiple studies show that 13 out of 30 cases

Table I Initial and final visual acuity

\begin{tabular}{|c|c|c|c|}
\hline Case number & Author & Initial VA & Final VA \\
\hline \multirow[t]{2}{*}{1} & Brandonisio and & 1.2 & 1.2 \\
\hline & Newman $^{3}$ & & \\
\hline 2 & Kamei et $\mathrm{al}^{4}$ & 0.1 & I \\
\hline 3 & Masaoka et $\mathrm{al}^{5}$ & 0.04 & 0.3 \\
\hline 4 & & 0.2 & 1 \\
\hline 5 & & 0.1 & 1.5 \\
\hline 6 & Takaya et $\mathrm{al}^{6}$ & 0.2 & 1.2 \\
\hline 7 & & 0.06 & 0.7 \\
\hline 8 & & 0.09 & I \\
\hline 9 & & LP & 0.06 \\
\hline 10 & Inoue et $\mathrm{al}^{7}$ & 0.6 & 1.2 \\
\hline II & & 0.5 & 1.2 \\
\hline 12 & & 0.5 & 1.2 \\
\hline 13 & & 0.5 & 1.2 \\
\hline 14 & & 0.2 & 0.6 \\
\hline 15 & & 0.1 & 0.5 \\
\hline 16 & & 0.2 & 1.2 \\
\hline 17 & & 0.3 & 1.2 \\
\hline 18 & & 0.3 & 0.9 \\
\hline 19 & & 0.1 & 0.8 \\
\hline 20 & & 0.2 & 0.4 \\
\hline 21 & & 0.3 & 0.1 \\
\hline 22 & Yuen et $\mathrm{al}^{8}$ & 0.1 & 0.3 \\
\hline 23 & Fujiwara et al ${ }^{9}$ & 0.2 & 0.9 \\
\hline 24 & & 0.08 & 0.3 \\
\hline 25 & Mandava et $a^{10}$ & $\mathrm{CF}$ & 0.1 \\
\hline 26 & Adachi et al" & 0.1 & 0.6 \\
\hline 27 & & 0.1 & 0.9 \\
\hline 28 & Inukai et al ${ }^{12}$ & 0.04 & 0.6 \\
\hline 29 & & 0.5 & I \\
\hline 30 & & 0.1 & 0.3 \\
\hline
\end{tabular}

Abbreviations: VA, visual acuity; LP, light perception; CF, counting fingers. 
reached a final visual acuity of 1.0 (Table 1). ${ }^{3-12}$ This is a high rate of visual improvement in traumatic hypotony maculopathy.

As confirmed by previous studies, ${ }^{13,17}$ it seems that the type of treatment varies depending on severity of the disease. However, some cases will require multiple surgeries due to the difficulty in accurately assessing disease severity. With more cases and the accumulation of more data, effective and noninvasive treatment methods are expected to be established in the future.

\section{Disclosure}

The authors report no conflicts of interest in this work.

\section{References}

1. Dellaporta A. Creasing of retina in hypotonia. Klin Monbl Augenheilkd Augenarztl Fortbild. 1954;125(6):672-678. [German].

2. Costa VP, Arcieri ES. Hypotony maculopathy. Acta Ophthalmol Scand. 2007;85(6):586-597.

3. Brandonisio TM, Newman TL. Hypotonous maculopathy and normal visual acuity secondary to post-traumatic cyclodialysis cleft. Optometry. 2002;73(10):620-625.

4. Kamei C, Kato T, Tsukamoto H, et al. A case of traumatic cyclodialysis followed by ultrasound biomicroscopy. Hiroshima J Med Sci. 2002; 51(3):81-84.

5. Masaoka N, Sawada K, Komatsu T, et al. Indocyanine green angiographic findings in 3 patients with traumatic hypotony maculopathy. Jpn $J$ Ophthalmol. 2000;44(3):283-289.
6. Takaya K, Suzuki Y, Nakazawa M. Four cases of hypotony maculopathy caused by traumatic cyclodialysis and treated by vitrectomy, cryotherapy, and gas tamponade. Graefes Arch Clin Exp Ophthalmol. 2006;244(7):855-858.

7. Inoue $\mathrm{E}$, Tokuda $\mathrm{N}$, Inoue $\mathrm{J}$, et al. Treatment of prognostic factors in case of hypotonic maculopathy caused by blunt trauma. Japanese Journal of Ophthalmic Surgery. 2007;20(1):131-137.

8. Yuen NS, Hui SP, Woo DC. New method of surgical repair for 360-degree cyclodialysis. J Cataract Refract Surg. 2006;32(1):13-17.

9. Fujiwara T, Yago K, Kato K. Sulucus-fixed intraocular lens implantation for traumatic hypotony maculopathy. Japanese Review of Clinical Ophthalmolgy. 2001;96(3):219-223.

10. Mandava N, Kahook MY, Mackenzie DL, et al. Anterior scleral buckling procedure for cyclodialysis cleft with chronic hypotony. Ophthalmic Surg Lasers Imaging. 2006;37(2):151-153.

11. Adachi M, Takeuchi M, Takahashi K, et al. Surgical treatment for hypotony maculopachy due to blunt trauma. Japanese Journal of Ophthalmic Surgery. 1997;10(2):275-278.

12. Inukai A, Tanaka S, Hirose A, et al. Three case of hypotonic maculopathy due to blunt trauma, treated by 360-degree scleral buckling. J Jpn Opthalmol Soc. 2003;107(6):337-342. [Japanese].

13. Brown S, Mizen T. Transscleral diode laser therapy for traumatic cyclodialysis cleft. Ophthalmic Surg Lasers. 1997;28(4):313-317.

14. Chandler PA, Maumenee AE. A major cause of hypotony. Am J Ophthalmol. 1961;52:609-618.

15. Weitgasser U, Wackernagel W, Oetsch K. Visual outcome and ocular survival after sports related ocular trauma in playing golf. $J$ Trauma. 2004;56(3):648-650.

16. Townley D, Kirwan C, O'Keefe M. Golf - recognising the risk of severe eye injury. Ir Med J. 2008;101(6):167-169.

17. González Martín-Moro J, Muñoz-Negrete FJ, Rebolleda G, et al. Ultrasonic biomicroscopic findings after spontaneous resolution of a traumatic cyclodialysis. Arch Soc Esp Oftalmol. 2003;78(4):211-214. [Spanish].
Clinical Ophthalmology

\section{Publish your work in this journal}

Clinical Ophthalmology is an international, peer-reviewed journal covering all subspecialties within ophthalmology. Key topics include: Optometry; Visual science; Pharmacology and drug therapy in eye diseases; Basic Sciences; Primary and Secondary eye care; Patient Safety and Quality of Care Improvements. This journal is indexed on

\section{Dovepress}

PubMed Central and CAS, and is the official journal of The Society of Clinical Ophthalmology (SCO). The manuscript management system is completely online and includes a very quick and fair peer-review system, which is all easy to use. Visit http://www.dovepress.com/ testimonials.php to read real quotes from published authors. 